\title{
In vitro intestinal permeability studies, pharmacokinetics and tissue distribution of 6-methylcoumarin after oral and intraperitoneal administration in Wistar rats
}

\author{
Paola Andrea Cárdenas ${ }^{1}$, Jadel Müller Kratz ${ }^{2}$, Aura Hernández ${ }^{1}$, Geison Modesti Costa ${ }^{3}$, Luis \\ Fernando Ospina ${ }^{4}$, Yolima Baena ${ }^{1}$, Cláudia Maria Oliveira Simões ${ }^{2}$, Álvaro Jimenez-Kairuz \\ Marcela Aragon $^{1 *}$
}

\begin{abstract}
${ }^{1}$ Grupo Sistemas de Liberación Modificada de Moléculas Biológicamente Activas, Departamento de Farmacia, Universidad Nacional de Colombia, Bogotá, Colombia, ${ }^{2}$ Grupo de Análise e Desenvolvimento de Fármacos de Origem Natural, Departamento de Ciências Farmacêuticas, Universidade Federal de Santa Catarina - UFSC, SC, Florianópolis, Brasil, ${ }^{3}$ Grupo de Estudio y Aprovechamiento de Productos Naturales Marinos y Frutas de Colombia Departamento de Química, Universidad

Nacional de Colombia, Bogotá, Colombia, ${ }^{4}$ Grupo de Principios Bioactivos de Plantas Medicinales, Departamento de

Farmacia, Universidad Nacional de Colombia, Bogotá, Colombia, ${ }^{5}$ Unidad de Investigación y Desarrollo en Tecnología Farmacéutica (UNITEFA), CONICET and Departamento de Farmacia, Facultad de Ciencias Químicas, Universidad Nacional de Córdoba. Ciudad Universitaria, Córdoba, Argentina
\end{abstract}

\begin{abstract}
6-Methylcoumarin (6MC) is a semisynthetic coumarin with important in vitro and in vivo antiinflammatory activity. In order to continue the pre-clinical characterization of this molecule, in vitro intestinal permeability, plasma profile and tissue distribution after oral administration in rats were studied. The permeability of 6MC was evaluated by the Caco-2 cellular model in both the apical-basal (A-B) and basal-apical (B-A) directions. The pharmacokinetics and biodistribution were evaluated in rats after oral and intraperitoneal administration at doses of $200 \mathrm{mg} / \mathrm{kg}$. Transport experiments with Caco-2 cells showed that $6 \mathrm{MC}$ presented high permeability at all concentrations evaluated. This finding suggested that $6 \mathrm{MC}$ could be transported across the gut wall by passive diffusion. The plasma concentration-time curve showed that the maximum concentration (Cmax) was $17.13 \pm 2.90 \mu \mathrm{g} / \mathrm{mL}$ at maximum time (Tmax) of $30 \mathrm{~min}$ for the oral route and Cmax $26.18 \pm 2.47 \mu \mathrm{g} / \mathrm{mL}$ at $6.0 \mathrm{~min}$ for the intraperitoneal administration, with elimination constant of $\left(K_{e}\right) 0.0070 \mathrm{~min}^{-1}$ and a short life half time of $\left(T_{1 / 2}\right)$ lower that $120 \mathrm{~min}$. The distribution study showed that $6 \mathrm{MC}$ has high accumulation in the liver, and widespread distribution in all the organs evaluated.
\end{abstract}

Uniterms: 6-Methylcoumarin/Pharmacokinetics/rats. 6-Methylcoumarin/distribution. Intestinal permeability/study. Intestinal permeability/study/In vitro.

\section{INTRODUCTION}

The oral route is the most common route for administration of new drugs, as it is considered the safest and most convenient. However, it also has limitations, as the drug must be absorbed from the site of absorption to the systemic circulation, and then distributed to the target organs, in order to produce its pharmacological effect (Hedaya, 2007).

\footnotetext{
*Correspondence: M. Aragón. Departamento de Farmacia. Universidad Nacional de Colombia. Carrera 30 número 45-03, Oficina 312, Bogotá, Colombia. N. Tel.: +57(1)3165000 Ext. 14630. E-mail: dmaragonn@unal.edu.co
}

According to the Biopharmaceutics Classification System (BCS) of the US Food and Drug Administration, drugs are classified based on two intrinsic properties that control their oral absorption: aqueous solubility and intestinal permeability (Amidon et al., 1995). Knowledge of these drug properties not only assists in the classification of a drug in the BSC, but also guides the selection of candidate drugs during the drug development process (Griffin, O’Dricoll, 2008).

Solubility is one of the properties that most influences bioavailability due to its role in dissolution process according to the Noyes Whitney (Jambhekar, Breen, 2013). Since solubility is a thermodynamic 
parameter that defines the amount of material that can dissolve in a given solvent at equilibrium, it is one of the most critical and widely studied physical-chemical attributes of candidate drugs (Wei-Qin, 2008).

Permeability, meanwhile, is the property that determines the speed at which a dissolved drug passes through the intestinal wall and reaches the systemic circulation. Permeability is considered one of most important features in the absorption of drugs. This is a complex kinetic process dependent on several physiological, physiochemical properties of the drug, and on the biophysiochemical properties of a gastrointestinal barrier membrane. Different mechanisms of permeation through biological barriers have been described, the most important ones being passive diffusion (transcellular and paracellular), active uptake, and efflux transport (Fagerholm, 2007; Matsson et al., 2005).

Likewise, knowledge of the pharmacokinetic profiles allows us to characterize compounds in terms of their bioavailability and desirable action of duration. Four pharmacokinetic (PK) parameters are the most useful in characterizing the in vivo disposition of a compound: (i) clearance ( $\mathrm{Cl}$, units of volume/time), a measure of the ability of the body to eliminate a compound; (ii) volume of distribution ( $\mathrm{Vd}$, units of volume), the apparent volume/ space in the body that contains the compound; (iii) halflife ( $t_{1 / 2}$, units of time), the time taken for a compound to decrease to half of its initial concentration in the fluid or tissue in which it is measured in (e.g., plasma), and (iv) bioavailability (F, unitless, often expressed as \%), the fraction of a compound that reaches the systemic circulation following non-intravenous administration (Fan, De Lannoy, 2014). Meanwhile, biodistribution studies describe the transit of a drug through the organism, the anatomic sites reached by the drug when it is in the systemic circulation, and the sites where it can accumulate (Hedaya, 2007).

On the other hand, some simple and complex coumarins have shown different biological activities, such as antibacterial, effects on the cardiovascular system, effects on the central nervous system, antioxidant activities, cytotoxicity, and anti-inflammatory properties (Grazul, Budzisz, 2009; Kidane et al., 2004; Beillerot et al., 2008; Anand, Singh, Singh, 2012; Sashidhara et al., 2011; Kang et al., 2009; Li et al., 2011; Hoult, Paydt, Paya, 1996). Furthermore, 6-methylcoumarin (6MC, Figure 1), another simple coumarin, has shown important anti-inflammatory activity in in vivo and in vitro models (Cárdenas et al., 2014).

Although $6 \mathrm{MC}$ has shown remarkable pharmacological effect, knowledge of its permeability,

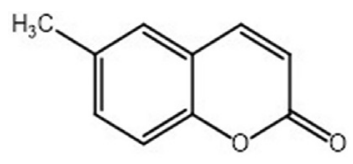

FIGURE 1 - Chemical structure of 6-methylcoumarin.

concentration-time and distribution is essential for understanding its biopharmaceutical profile. Thus, the aim of this work was to study the in vitro permeability and in vivo pharmacokinetics after oral and intraperitoneal administration in Wistar rats, in order to complete the biopharmaceutical characterization of $6 \mathrm{MC}$.

\section{MATERIAL AND METHODS}

\section{Chemical reagents}

6-Methylcoumarin (6MC, Sigma; St. Louis, MO, USA); trichloroacetic acid (Analytical grade, Merck, Darmstadt, Germany); acetic acid, methanol (HPLC grade, Merck, Darmstadt, Germany), and water HPLC grade were prepared by the MilliQ Plus system (Millipore Co., France).

\section{Animals}

Twelve-week-old Male Wistar rats were obtained from the animal house of the Pharmacy Department of the Universidad Nacional de Colombia. The assays were carried out in accordance with the international and local ethical guidelines on the use and care of laboratory animals. The local Research Ethics Committee (Act 03/2012 Faculty of Science) approved this study.

\section{Drug analysis}

For all the analyses, an Agilent 1100 Series HPLC chromatograph was used. For the permeability studies, a Phenomenex reversed phase column (Macclesfield, UK) Bondclone C-18 (150 x $3.9 \mathrm{~mm} ; 10 \mu \mathrm{m})$ was used. The mobile phase was composed of A) water: methanol: acetic $\operatorname{acid}(95: 5: 1 \mathrm{v} / \mathrm{v})$ and B): methanol: acetic acid (100:1 v/v); ratio 80:20 (A:B), under isocratic flow $1.0 \mathrm{~mL} / \mathrm{min}$. The analytical wavelength was $321 \mathrm{~nm}$, and samples of $10 \mu \mathrm{L}$ were injected.

For the pharmacokinetics and tissue distribution, a Phenomenex reversed phase column (Macclesfield, UK) Bondclone C-18 (150 x $3.9 \mathrm{~mm} ; 10 \mu \mathrm{m})$ was used. The mobile phase was composed of A) water: methanol: acetic acid (95:5:1 v/v) and B): methanol: acetic acid (100:1 $\mathrm{v} / \mathrm{v}$ ) as gradient, for $32 \mathrm{~min}$, at a flow rate of $1 \mathrm{~mL} / \mathrm{min}$, as 
follows: 0 to $14 \mathrm{~min}: 0 \% \mathrm{~B}$ to $50 \% \mathrm{~B}$; 14 to $23 \mathrm{~min}: 50 \%$ B; 23 to 24 min: $50 \%$ B to $0 \% \mathrm{~B} ; 24$ to $32 \mathrm{~min}: 0 \% \mathrm{~B}$. UV detection was performed at $321 \mathrm{~nm}$. The injection volume was $50 \mu \mathrm{L}$. The data were processed using the software program Value Solution Chemstation ${ }^{\circledR}$ (ChemStation for LC 3D systems Rev. B.03.02 [341]) (Hernández, Ospina, Aragón, 2014).

\section{Caco-2 permeability studies}

\section{Cell culture}

Caco-2 cells (ATCC:HTB-37) were cultured in high-glucose DMEM (Gibco, USA) supplemented with $10 \%$ fetal bovine serum and $1 \%$ non-essential amino acids (Gibco, USA), at $37{ }^{\circ} \mathrm{C}$ in a humidified $5 \% \mathrm{CO}_{2}$ atmosphere, until the cells reached $80-90 \%$ confluence. For the transport experiments, 100,000 cells (passages 113-115) were harvested and seeded on each polycarbonate insert $\left(0.6 \mathrm{~cm}^{2}, 0.4 \mu \mathrm{m}\right.$ pore size; Millipore, USA), and allowed to grow and differentiate for 21-28 days prior to the experiments, as described previously by Kratz et al. (2012).

\section{Transport experiments}

The determination of in vitro intestinal permeability of $6 \mathrm{MC}$ was carried out under sink conditions in a series of $\mathrm{pH}$-gradient bidirectional transport experiments with Caco- 2 cells. Before the experiments, cell monolayers were rinsed with Hank's balanced salt solution (HBSS) and equilibrated for $30 \mathrm{~min}$ at $37^{\circ} \mathrm{C}$. The integrity of the monolayers was assessed before and after the experiments, by transepithelial electrical resistance (TEER) measurement. Only monolayers with TEER values above $200 \Omega \mathrm{cm}^{2}$ were considered.

A stock solution of $6 \mathrm{MC}(10 \mathrm{mM}$ DMSO) was diluted to final concentration of $10,25,50$ or $100 \mu \mathrm{M}$ in HBSS pH 6.5 (apical transport buffer) or $\mathrm{pH} 7.4$ (basolateral transport buffer). Bidirectional experiments (apical-to-basolateral [AB] and basolateral-to-apical [BA]) were initiated by adding $6 \mathrm{MC}$ solutions to the donor compartment, and fresh buffer to the acceptor compartment. Caco-2 cell monolayers were incubated for $1 \mathrm{~h}$ at $37^{\circ} \mathrm{C}$ under constant stirring (150 rpm). Receiver compartments were sampled at $0,15,30,45$ and $60 \mathrm{~min}$, refilled with an equivalent amount of transport buffer, and samples were submitted to analysis by HPLC/UV. Apparent permeability coefficients $\left(P_{\text {app }}\right)$ were calculated from the equation

$$
P_{a p p}=\frac{\Delta \mathrm{Q}}{\Delta \mathrm{t}} \times \frac{1}{A C_{0}}
$$

where $\Delta Q / \Delta t$ is the steady-state flux $(\mathrm{mol} / \mathrm{s}), C_{0}$ is the initial concentration in the donor chamber at each time interval ( $\mathrm{mol} / \mathrm{mL})$, and $A$ is the surface area of the filter $\left(\mathrm{cm}^{2}\right)$. Carbamazepine (CBZ) $(50 \mu \mathrm{M})$ and hydrochlorothiazide (HCT) $(200 \mu \mathrm{M})$ were used as controls. The data are presented as means $\pm \mathrm{SD}$ of six independent monolayers.

\section{Pharmacokinetic study}

Male Wistar rats (12 weeks, $250 \pm 10 \mathrm{~g}$ ), with 5 animals for each administration route, were administrated, by oral gavage (p.o.) or intraperitoneal (i.p.) route, with $6 \mathrm{MC}$ at $200 \mathrm{mg} / \mathrm{Kg}$, suspended in saline solution $(\mathrm{NaCl} 0.9$ $\%$ ) and tween-80. $200 \mathrm{mg} / \mathrm{kg}$ was chosen as doses, since in previous assays (data not shown) the biopharmaceutics parameter, Tmax, Cmax and AUC proved be linear in a range of dose of 100 to $400 \mathrm{mg} / \mathrm{kg}$.

Blood samples, $400 \mu 1$, were collected from the retro-orbital sinus, at 2,6,10,15,20,25,30,45,60,120, 360 and $480 \mathrm{~min}$ after oral administration. After each sampling, the blood samples were centrifuged at $6000 \mathrm{rpm}$ for 10 min, at $4{ }^{\circ} \mathrm{C}$ to separate the plasma, and then $200 \mu \mathrm{L}$ of plasma was homogenized with $200 \mu \mathrm{L}$ of trichloroacetic acid $(20 \%)$, and centrifuged at $13000 \mathrm{rpm}$ for $10 \mathrm{~min}$. The supernatant was recovered for $6 \mathrm{MC}$ quantification using the HPLC-DAD method previously described. The maximal observed plasma concentration (Cmax) and corresponding sampling time (Tmax) were determined by visual inspection of the data.

The apparent elimination rate constant $\left(K_{e}\right)$ was estimated by linear regression of the log-transformed plasma concentrations during the terminal log-linear decline phase. The apparent terminal elimination half-life time $\left(t_{1 / 2}\right)$ was calculated as $\ln 2 / K_{e}$. The area under the $6 \mathrm{MC}$ plasma concentration-time curve from time zero to the last quantifiable point $\left(A U C_{0-t}\right)$ was calculated using the linear trapezoidal rule. The AUC extrapolated to infinity $\left(A U C_{0-\alpha}\right)$ was calculated as the sum of $A U C_{0-t}$, and the last quantifiable point was divided by the elimination rate constant. The apparent oral clearance $(\mathrm{Cl} / f)$ was calculated as the dose divided by $A U C_{0-\alpha .}$ The apparent volume of distribution $(V / F)$ was calculated as the apparent oral clearance divided by the elimination constant.

\section{Tissue distribution study}

Male Wistar rats $(12$ weeks, $250 \pm 10 \mathrm{~g})$ were administered $6 \mathrm{MC}$ at $200 \mathrm{mg} / \mathrm{kg}$ by oral gavage (p.o.), suspended in saline solution ( $\mathrm{NaCl} 0.9 \%)$. At 15, 30, 60 and $120 \mathrm{~min}$ after oral administration, the animals were sacrificed by cervical dislocation (five animals for each 
sampling time). The organs (liver, heart, lung, kidney and spleen) were removed and washed with saline solution. The organs were then homogenized with a same volume of trichloroacetic acid (20\%) in a Polytron PT-10 - 35 (Kinematica, Newark, NJ, USA), and centrifuged at 13000 $\mathrm{rpm}$ for $10 \mathrm{~min}$. The supernatanat was recovered for $6 \mathrm{MC}$ quantification.

\section{Identification of the main 6-methylcoumarin metabolite}

To determine possible metabolites of 6MC after oral administration, the plasma samples were analyzed by LC-ESI/MS. The system consisted of a Shimadzu HPLC equipped with two isocratic pumps, on-line degasser, a Rhodyne manual injector, a UV detector and a mass spectrometer (Shimadzu LCMS-2010EV). The chromatographic parameters were the same as those used in the HPLC-DAD analysis. LabSolution ${ }^{\circledR}$ V.3.0 software was used for the data acquisition and processing. Full scan mass spectra were recorded at between $\mathrm{m} / \mathrm{z} 50$ and 500 in positive mode. Nitrogen was used as nebulizer gas at $1 \mathrm{~L} /$ min, capillary voltage was $4.500 \mathrm{~V}$ and detector voltage was $1.500 \mathrm{~V}$. The collision dissolution line (CDL) and QarrayRF voltage were both $150 \mathrm{~V}$. CDL and the Heat Block temperature as set at $250^{\circ} \mathrm{C}$. Standard samples of coumarin and $6 \mathrm{MC}$ were analyzed following the same methodology.

\section{Statistical analysis}

All results were expressed as the arithmetic mean of the values obtained, \pm the respective standard deviation. Simple comparisons between groups were performed using the Student's t-test, with a confidence level of $95 \%$.

\section{RESULTS}

\section{Permeability}

Table I shows that $6 \mathrm{MC}$ presented a high $P_{a p p}$ in the absorptive and secretory directions in Caco -2 cells. Given the finding of $P_{a p p}$ values over $10^{-5}$, it is suggested that $6 \mathrm{MC}$ is highly permeable in both directions. The efflux ratio $\left(P_{a p p \mathrm{BA}} / P_{a p p \mathrm{AB}}\right)$ of less than 2 in all cases indicates a passive diffusion mechanism and the absence of efflux. For all the concentrations evaluated, $6 \mathrm{MC}$ had high mass balance values, with average recovery of more than $70 \%$ in both the $\mathrm{AB}$ and $\mathrm{BA}$ directions.

The permeation of $6 \mathrm{MC}$ was performed in both $\mathrm{A}-\mathrm{B}$ and $\mathrm{B}-\mathrm{A}$ in the Caco- 2 cellular model. Figure 2 shows the cumulative amount permeated $\left(\mu \mathrm{M} / \mathrm{cm}^{2}\right)$ in the $A B$ and $\mathrm{BA}$ directions. The relation of the concentration versus the cumulative amount permeated showed a linear relationship proportional to concentration (in both directions), with determinant coefficients of 0.9903 and 0.9853 for $\mathrm{AB}$ and $\mathrm{BA}$ direction, respectively. This means that there is no saturation of the acceptor medium in any concentration and time during the test time.

\section{Pharmacokinetic}

The plasma samples were analyzed using an HPLCDAD validated method (Hernández, Ospina, Aragón, 2014). The mean plasma concentration versus time profiles of $6 \mathrm{MC}$ are shown in Figure 3. The pharmacokinetic parameters calculated for $6 \mathrm{MC}$ in plasma are summarized in Table II.

Plasma pharmacokinetics of 6-methylcoumarin in rats following oral administration. Data are expressed as mean \pm SD of five animals. Dose administered $200 \mathrm{mg} / \mathrm{kg}$.

TABLE I - Comparable $P_{a p p}(\mathrm{~cm} / \mathrm{s})$ values for 6MC obtained in the absorptive (A-B), secretory (B-A) directions, and efflux ratio $\left(P_{a p p} \mathrm{~B}-\mathrm{A} / P_{a p p} \mathrm{~A}-\mathrm{B}\right)$

\begin{tabular}{|c|c|c|c|c|c|}
\hline & \multicolumn{2}{|c|}{ A-B } & \multicolumn{2}{|c|}{ B-A } & \multirow{2}{*}{ Efflux ratio } \\
\hline & Mean & SD & Mean & SD & \\
\hline $10 \mu \mathrm{M}$ & $9.1 \mathrm{E}-05$ & $2.9 \mathrm{E}-06$ & $1.3 \mathrm{E}-04$ & $6.1 \mathrm{E}-05$ & 1.48 \\
\hline $25 \mu \mathrm{M}$ & $6.8 \mathrm{E}-05$ & 2.4E-06 & $6.7 \mathrm{E}-05$ & $1.4 \mathrm{E}-06$ & 1.06 \\
\hline $50 \mu \mathrm{M}$ & $6.4 \mathrm{E}-05$ & 8.3E-06 & $6.0 \mathrm{E}-05$ & $5.6 \mathrm{E}-07$ & 0.94 \\
\hline $100 \mu \mathrm{M}$ & $9.0 \mathrm{E}-05$ & 4.4E-06 & 7.3E-05 & $1.5 \mathrm{E}-05$ & 0.82 \\
\hline $\mathrm{CBZ} 50 \mu \mathrm{M}$ & 11.4E-05 & $2.4 \mathrm{E}-06$ & & & \\
\hline НCТ $200 \mu \mathrm{M}$ & $0.06 \mathrm{E}-05$ & $0.3 \mathrm{E}-07$ & & & \\
\hline
\end{tabular}

The data are expressed as means \pm SD of six independent monolayers. Carbamazepine (CBZ) (50 $\mu \mathrm{M})$ and hydrochlorothiazide (HCT) $(200 \mu \mathrm{M})$ were used as controls. 

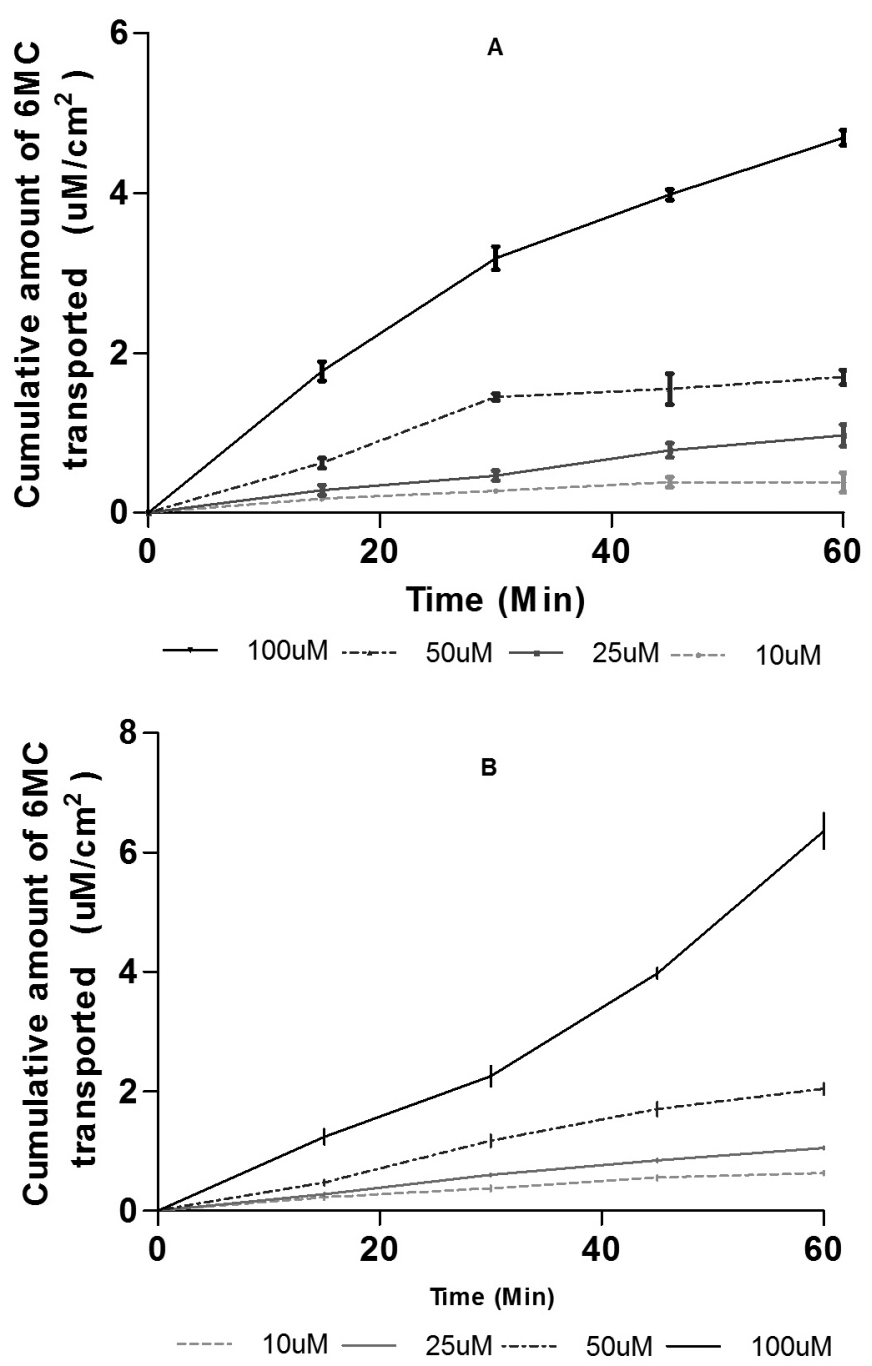

FIGURE 2 - Transport of 6-methylcoumarin across Caco-2 cells. Cumulative amount of 6-methylcoumarin transported across Caco-2 cells in the Apical to Basolateral (A) or Basolateral to Apical direction (B). Data are expressed as means $\pm \mathrm{SD}$ of six independent monolayers.

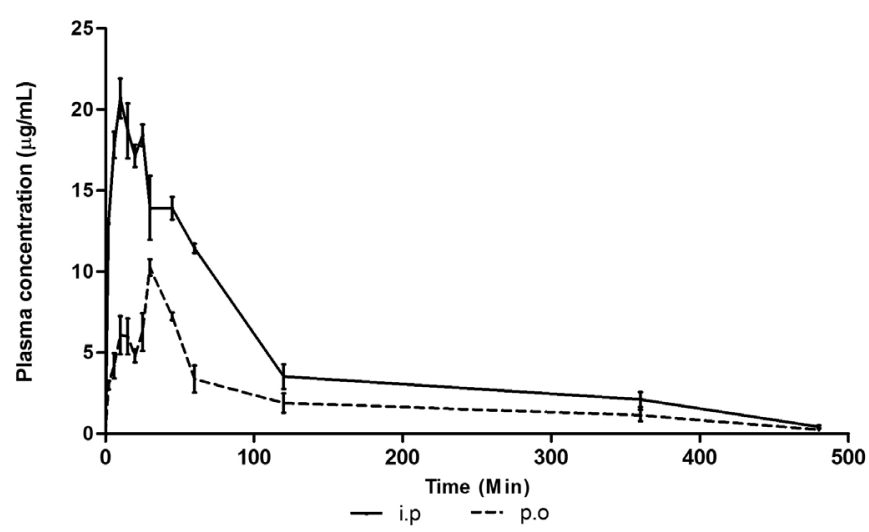

FIGURE 3 - Plasma concentration - time profile of 6-methylcoumarin after oral and intraperitoneal administration in Wistar rats.

Maximum concentration (Cmax), Maximun time (Tmax), Area Under Curve from time zero to the last quantifiable point $\left(A U C_{0-480}\right)$, Area Under Curve extrapolated to infinite $\left(A U C_{0-\alpha}\right)$, Elimination constant $\left(K_{e}\right)$, Absortion constant $\left(K_{a}\right)$, elimination half -time $\left(t_{1 / 2}\right)$, Apparent oral clearance $(\mathrm{Cl} / \mathrm{F})$, Apparent volume of distribution $(V / F) . \mathrm{Cl} / \mathrm{f}$ and $\mathrm{Vd}$ were calculated taking into account the soluble $6 \mathrm{MC}$ in the volume administered. The data are generated using the mean values from individual rats $\pm \mathrm{SD}(\mathrm{n}=5)$.

As shown in Table II, the Cmax, Tmax, and $\mathrm{ABC}_{0}$ ${ }_{480}$ and $\mathrm{ABC}_{0-\alpha}$ values for intraperitoneal administration are higher than those obtained after oral administration. This fact could be explained by that fact that in the intraperitoneal route, absorption occurs through the mesenteric vessels, draining to the portal vein, and thereby accessing the bloodstream in less time than by the oral route (Turner et al., 2011), making this a more rapid absorption route (Morton et al., 2001).

TABLE II - Plasma pharmacokinetics parameters of 6-methylcoumarin after oral and intraperitoneal administration in Wistar rats, dose $200 \mathrm{mg} / \mathrm{kg}$

\begin{tabular}{|c|c|c|}
\hline & Oral & Intraperitoneal \\
\hline$A U C_{0-480}(\mu \mathrm{g} / \mathrm{mL} * \min )$ & $977.2 \pm 276.5$ & $2177.0 \pm 331.6$ \\
\hline$A U C_{0-a}\left(\mu \mathrm{g} / \mathrm{mL}^{*} \mathrm{~min}\right)$ & $1015.4 \pm 296.1$ & $2234.9 \pm 354.1$ \\
\hline $\mathrm{C} \max (\mu \mathrm{g} / \mathrm{mL})$ & $17.13 \pm 2.90$ & $26.18 \pm 2.47$ \\
\hline $\operatorname{Tmax}(\min )$ & 30 & 6.0 \\
\hline$k_{e}\left(\min ^{-1}\right)$ & $0.0064 \pm 0.0009$ & $0.0076 \pm 0.0007$ \\
\hline$K_{a}\left(\min ^{-1}\right)$ & $0.3311 \pm 0.0489$ & \\
\hline$t_{1 / 2}(\min )$ & $109.8 \pm 15.0$ & $92.3 \pm 8.7$ \\
\hline $\mathrm{Cl} / \mathbf{f}(\mathbf{m L} / \mathbf{m i n})$ & $0.8 \pm 0.3$ & $0.4 \pm 0.07$ \\
\hline Vd $(m L)$ & $134.9 \pm 30.4$ & $48.8 \pm 3.9$ \\
\hline $\mathbf{F}$ & 0.45 & \\
\hline
\end{tabular}


TABLE III - The main coumarinic compounds identified by LC-ESI/MS analysis in plasma after oral administration of 6-methylcoumarin in Wistar rats

\begin{tabular}{ccccc}
\hline Peak & Rt $(\mathbf{m i n})$ & $\boldsymbol{\lambda}_{\text {max }}(\mathbf{n m})$ & {$[\mathbf{M}+\mathbf{H}]+(\boldsymbol{m} / \mathbf{z})$} & Compound \\
\hline 1 & 12.5 & 278 and 321 & 147 & Coumarin \\
2 & 14.6 & 278 and 321 & 161 & 6-methylcoumarin \\
\hline
\end{tabular}

Regarding the values obtained of $k_{e}, \mathrm{t}_{1 / 2}$ and the $\mathrm{Cl} / \mathrm{f}$, no significant difference was found that could be attributed to the administration route. This fact is expected, since these are intrinsic parameters of the drug.

Besides 6MC, another majority compound was detected in the plasma after oral administration of $6 \mathrm{MC}$. This compound could be related to gastrointestinal metabolism of $6 \mathrm{MC}$, since it was not found in the blood samples analyzed after i.p. administration. Data from the LC-ESI/MS were used for preliminary identification of the main metabolite of 6-MC. The retention times (Rt), $\mathrm{UV} \lambda_{\max }$ values and the molecular ions in positive mode are shown in Table III.

\section{Distribution Tissue}

Using a validated HPLC-DAD method, the concentration of $6 \mathrm{MC}$ after oral administration was determined in liver, heart, lung, kidney and spleen (Figure 4).

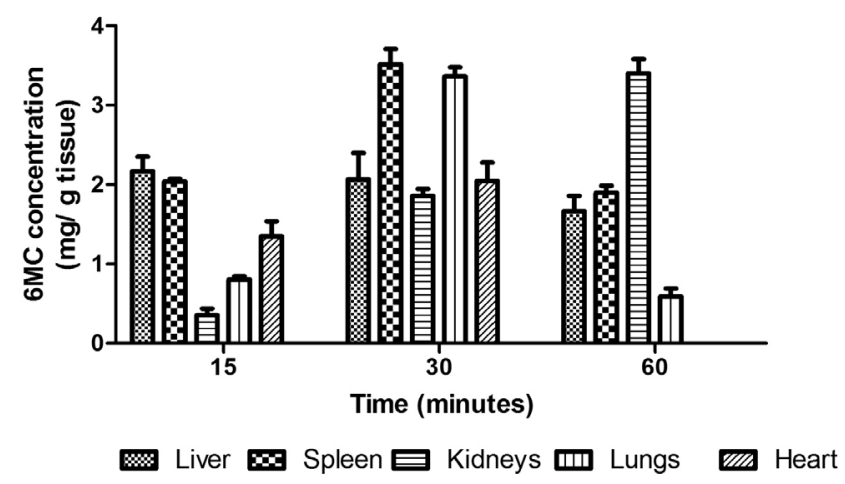

FIGURE 4 - Biodistribution profile of 6-methylcoumarin after oral administration in Wistar rats. Data expressed mean \pm D.S of five animals. Dose administered $200 \mathrm{mg} / \mathrm{kg}$.

In all the organs, $6 \mathrm{MC}$ concentrations were found to be in the range of between $0.35 \pm 0.14$ and $4.18 \pm 0.03$ $\mu \mathrm{g}$ per $\mathrm{g}$ of tissue. At $15 \mathrm{~min}$, the highest concentrations were found in plasma and liver, and the lowest in kidneys, heart and lungs. At $30 \mathrm{~min}$, the concentration increased proportionally in all the organs sampled. At $60 \mathrm{~min}$, the distribution changed; in the kidney, the concentration of
6MC increased significantly, while the concentrations in the other organs decreased. At this same time point, the concentrations $(\mu \mathrm{g} / \mathrm{mL})$ were as follows; heart: 2.54 \pm 0.10 ; plasma: $2.48 \pm 0.62$; spleen: $1.89 \pm 0.15$, lung: $0.59 \pm 0.10$ lung, kidney $3.40 \pm 0.31$, liver $1.45 \pm 0.10$. In addition, the $6 \mathrm{MC}$ fraction present in the evaluated organs was very low, since the total $6 \mathrm{MC}$ found in all the organs tested at 30 and 60 minutes was $0.104 \%$ and the $0.046 \%$ of the $6 \mathrm{MC}$ administered, respectively.

\section{DISCUSSION}

Ideal drug candidates should have adequate aqueous solubility and permeability in order to achieve effective concentration in the target tissue (Kratz et al., 2012). In order to evaluate the in vitro intestinal permeability, transport experiments were performed on Caco- 2 cells. These cells are able to fully polarize into differentiated monolayers, with well-established tight junctions and brush border membrane. They can also express several membrane transporters and metabolizing enzymes, allowing the measurement of functional permeability, both through passive diffusion and active transport (Kratz et al., 2012). The apparent permeability of $6 \mathrm{MC}$ was high, with values of magnitude of $10^{-5}$. This value is comparable with the $P_{a p p}$ of other similar compounds such as umbelliferone, scopoletine, and coumarin, in which high permeability and no efflux were reported (Galkin, Fallarero, Vuorela, 2009).

The high intestinal permeability of a drug indicates that its transport across the gut wall does not represent a relevant restriction for its oral absorption. The linear increase in the amount of $6 \mathrm{MC}$ permeated, indicating that its transport across the gut wall, is probably mediated by passive diffusion, and the low efflux values in the different concentrations evaluated, indicating that efflux does not represent an interference for absorption (Galkin, Fallarero, Vuorela, 2009).

The BCS considers that a drug has high aqueous solubility if its maximum dose is completed dissolved in $250 \mathrm{ml}$ of $\mathrm{pH} \mathrm{1-7.5} \mathrm{buffered} \mathrm{aqueous} \mathrm{solution} \mathrm{(Wei-}$ Qin, 2008). According to this definition, it is suggested that $6 \mathrm{MC}$ has low solubility, since the dose of $6 \mathrm{MC}$ that 
showed anti-inflammatory activity in rats is $200 \mathrm{mg} /$ $\mathrm{kg}$,(Cárdenas et al., 2014) and its solubility is $0.57 \pm 0.03$ $\mu \mathrm{g} / \mathrm{mL}$ in water and buffered solutions of $\mathrm{pH} 1.2,6.8$ and 7.4 (Cárdenas et al., 2013). As consequence, $6 \mathrm{MC}$ can be classified as a class II compound (Low solubility/High permeability) accord to the BCS, when the absorption across the gut wall is limited mainly by solubility.

The concentration-time profiles (Fig 3) showed fast absorption, but low plasma concentration in relation to the dose administered $(10.25 \pm 0.72$ y $26.18 \pm 2.47 \mu \mathrm{g} / \mathrm{mL}$ oral and intraperitoneal via respectively). This fact may be related to the high clearance rate $(C L / F)$ and possibly, a high rate of metabolism after administration of $6 \mathrm{MC}$.

Regarding other coumarins orally administered in rats, $6 \mathrm{MC}$ have a similar $t_{1 / 2}$ to that reported for daphnoterine and daphnetin $\left(t_{1 / 2}\right.$ of $93 \pm 26$ and \pm 262.23 96.31 min respectively) (Wei et al., 2015; Lin et al., 2005; Zhang et al., 2014). For coumarin, half-lives $\left(t_{1 / 2}\right)$ of between 60-240 h were found in humans and other species, such as rats (Lake, 1999).

The absolute bioavailability is defined as the fraction of administered dose that reaches the systemic circulation, compared to the fraction of intravenously administered dose, while the relative bioavailability is the fraction of administered dose that reaches the systemic circulation compared to an administration route other than the intravenous one (Haidar, Kwon, Lionberger, 2008 ). Due to the low solubility of $6 \mathrm{MC}$, its intravenous administration was not possible; therefore, the value reported for bioavailability in this study corresponds to the intraperitoneal route, a parenteral route with rapid absorption (Turner et al., 2011). The relative bioavailability found for $6 \mathrm{MC}$ was $0.45(45 \%)$ which is higher than that reported for coumarin administered orally in humans, which showed rapid absorption from the gastrointestinal tract and was rapidly metabolized by the first-pass effect, resulting in only 2-6\% found intact in the systemic circulation (Felter et al., 2006). Similarly, other authors have described the behavior of high metabolization and low plasma concentrations of coumarin, indicating an absolute bioavailability of only 1.5 \% (Hoult, Paydt, Paya, 1996).

As shown in Figure 4, in all the organs tested at $60 \mathrm{~min}$, the $6 \mathrm{MC}$ concentration decreased to half the initial concentration after $30 \mathrm{~min}$. This fact suggests that $6 \mathrm{MC}$ is rapidly eliminated from the systemic circulation $\left(t_{1 / 2}\right.$ less than 2 hour and high apparent clearance) or extensively metabolized. Previous studies on the in vivo metabolism of coumarins reported that coumarins are metabolized mainly into two kinds of compounds: its hydroxyl derivatives, and its smaller acid derivatives, such as ortho-hydroxyphenyllactic acid, ortho-hydroxyphenylacetic acid and orthohydroxyphenylpropionic acid (Lake, 1999).

In this study, some peaks presented pseudomolecular ions related to known coumarin metabolites. Although the highest peak observed (Rt $14.6 \mathrm{~min}$ ) was the non-metabolized 6MC, metabolites could be observed and tentatively identified, such as coumarin $(\mathrm{Rt}=12.5)$. These results suggest that demethylation is probably the primary biotransformation for $6 \mathrm{MC}$ in order to increase the polarity of the molecule. This demethylation reaction is reported for other compounds such as lobeglitazone (Song et al., 2014), and for the Ostol, a coumarinic compound where the demethylation has been described as a phase I metabolic reaction of (Yuan et al., 2009). Another peak $(\mathrm{Rt}=11.8,[\mathrm{M}+\mathrm{H}]+$ $(\mathrm{m} / \mathrm{z}) 657.3)$ was observed, but was not possible to propose a structure, because the molecular weight is not comparable with the common metabolites of coumarin structure. The conjugation with glutathione (GSH) is common for coumarin (Lake, 1999).

The biodistribution after oral administration in the studied organs evidenced a high accumulation of $6 \mathrm{MC}$ in the plasma and in the most irrigated organs; similar behavior was found for $6 \mathrm{MC}$ biodistribution after intraperitoneal administration (Hernández, Ospina, Aragón, 2014). High levels of accumulation were found in the liver and kidney, which suggests that these organs are involved in the processes of metabolism, elimination and excretion of $6 \mathrm{MC}$. The high accumulation in all organs evaluated is in concordance with the high $V d$ found both administration routes (p.o and i.p), indicating that $6 \mathrm{MC}$ is widely distributed throughout the body.

\section{CONCLUSION}

Some biopharmaceutical properties of $6 \mathrm{MC}$ were determined in order to increase the preclinical characterization of this promising drug. It was found that $6 \mathrm{MC}$ is highly permeable and according to the BCS, may be considered a compound class II. The biopharmaceutical and pharmacokinetic parameters were determined 6MC after oral and intraperitoneal administration in Wistar rats. It was found that the compound has a rapid removal times, as reflected in its short half-life of $110 \mathrm{~min}$ under constant removal of $0.0070 \mathrm{~min}^{-1}$. A large volume of distribution was also observed in the biodistribution study, indicating extensive distribution. Coumarin was identified as the major metabolite 6-methylcoumarin, suggesting desmetililation as the first reaction $6 \mathrm{MC}$ biotransformation. 


\section{ACKNOWLEDGEMENTS}

The authors thank the VRI and the DIB of the Universidad Nacional de Colombia (UNC) for their financial support. We also thank the Pharmaceutical Department of the UNC for providing the equipment and laboratories. JMK and CMOS thank the Brazilian funding agencies CAPES (PNPD 2207/2009, MEC) and CNPq (MCTI) for their research fellowships.

\section{CONFLICT OF INTEREST}

The author(s) declare(s) that they have no conflict of interest to disclose.

\section{REFERENCES}

AMIDON, G.L.; LENNERNÄS, H.; SHAH, VP.; CRISON, J.R. A theoretical basis for a biopharmaceutic drug classification: the correlation of in vitro drug product dissolution and in vivo bioavailability. Pharm. Res., v.12, n.3, p.413-420, 1995.

ANAND, P.; SINGH, B.; SINGH, N. A review on coumarins as acetylcholinesterase inhibitors for Alzheimer's disease. Bioorg. Med. Chem., v.20, n.3, p.1175-1180, 2012.

BEILLEROT, A.; DOMÍNGUEZ, J.C.; KIRSCH, G.; BAGREL, D. Synthesis and protective effects of coumarin derivatives against oxidative stress induced by doxorubicin. Bioorg. Med. Chem. Lett., v.18, n.3, p.1102-1105, 2008.

CÁRDENAS, P.A.; BARRERA, J.; HERNÁNDEZ, A.; OSPINA, L.F.; NOVOA, D.M. Effect of 6-Methylcoumarinloaded polycaprolactone microparticles on Carrageenan Paw edema in rats. Lat.Am. J. Pharm., v.33, n.4, p.550-556, 2014.

CÁRDENAS, P.A.; BAENA, Y.; ARAGÓN, D.M.; JIMÉNEZKAIRUZ, A.; MARTÍNEZ, F. Solution thermodynamics of 6-Methylcoumarin in aqueous media at several $\mathrm{pH}$ values. Lat. Am. J. Pharm., v.32, n.6, p.793-801, 2013.

FAGERHOLM, U. Prediction of human pharmacokinetics-gastrointestinal absorption. J. Pharm. Pharmacol., v.59, n.7, p.905-916, 2007.

FAN, J.; DE LANNOY, I.A.M. Pharmacokinetics. Biochem. Pharmacol., v.87, n.1, p.93-120, 2014.
FELTER, S.P.; VASALLO, J.; CARLTON, B.; DASTON, G. A safety assessment of coumarin taking into account speciesspecificity of toxicokinetics. Food Chem. Toxicol., v.44, n.4, p.462-475, 2006.

GALKIN, A.; FALLARERO, A.; VUORELA, P.M. Coumarins permeability in Caco-2 cell model. J. Pharm. Pharmacol., v.61, n.2, p.177-184, 2009.

GRAZUL, M.; BUDZISZ, E. Biological activity of metal ions complexes of chromones, coumarins and flavones. Coord. Chem. Rev., v.253, n.21, p.2588-2598, 2009.

GRIFFIN, B.; O'DRICOLL, C. Models of the small intestine. In: EHRHARDT, C.; JIN-KIM, K.(Eds) Drug absortions studies. New York: American Association of Pharmaceutical Scientists: Springer Science, 2008. p.34-65.

HAIDAR, S.H.; KWON, H.; LIONBERGER, R.; YU, L. Bioavailability and bioequivalence. In: KRISHNA, R.; YU, L. (eds.) Biopharmaceutics applications in drug development. New York: Springer, 2008. p.262-289.

HEDAYA, M. Basic pharmacokinetics. Boca Raton: Taylor and Francis Group, 2007. p.5.

HERNÁNDEZ, A.R.; OSPINA, L.F.; ARAGÓN, D.M. Biodistribution study of free and microencapsulated 6-methylcoumarin in Wistar rats by HPLC. Biomed. Chromatogr., v.29, n.2, p.176-181, 2014.

HOULT, J.R.S.; PAYDT, M.; PAYA, M. Pharmacological and biochemical actions of simple coumarins: Natural products with therapeutic potential. Gen. Pharmacol., v.27, n.4, p.713-722, 1996.

JAMBHEKAR, S.S.; BREEN, P.J. Drug dissolution: significance of physicochemical properties and physiological conditions. Drug Discov. Today, v.18, n.23, p.1173-1184, 2013.

KANG, K.H.; KONG, C.S.; SEO, Y.; KIM, M.; KIM, S. Antiinflammatory effect of coumarins isolated from Corydalis heterocarpa in HT-29 human colon carcinoma cells. Food Chem. Toxicol., v.47, n.8, p.2129-2134, 2009.

KIDANE, A.G.; SALANCINSKI, H.; TIWARI, A.; BRUCKDORFER, K.; SEIFALIAN, A. Anticoagulant and antiplatelet agents: their clinical and device applications together with usages to engineer surfaces. Biomacromolecules, v.5, n.3, p.798-813, 2004. 
KRATZ, J.M.; TEIXEIRA, M.R.; FERRONATO, K.; TEIXEIRA, H.F.; KOESTER, S.; SIMOES, C.M. Preparation, characterization, and in vitro intestinal permeability evaluation of thalidomide-hydroxypropylbeta-cyclodextrin complexes. AAPS PharmSciTech., v.13, n.1, p.118-124, 2012.

LAKE, B.G. Coumarin metabolism, toxicity and carcinogenicity: relevance for human risk assessment. Food Chem. Toxicol., v.37, n.4, p.423-453, 1999.

LI, Z.P.; HU, J.M.; SUN, M.N.; JI, H.J.; ZHAO, M.; WU, D.H.; LI, G.Y.; LUI, G.; CHEN, N.H. Effect of compound IMMLG5521, a novel coumarin derivative, on carrageenaninduced pleurisy in rats. Eur. J. Pharmacol., v.661, n.1/3, p.118-123, 2011.

LIN, L.-C.; YANG, K.I.; CHEN, Y.F.; WANG, S.C.; TSAI, T.H. Measurement of daphnoretin in plasma of freely moving rat by liquid chromatography. J. Chromatogr. A., v.1073, n.1/2, p.285-289, 2005.

MATSSON, P.; BERGSTRÖM, C.A.; NAGAHARA, N.; TAVELIN, S.; NORINDER, U.; ARTURSSON, P. Exploring the role of different drug transport routes in permeability screening. J. Med. Chem., v.48, n.2, p.604613, 2005.

MORTON, D.B.; JENNINGS, M.; BUCKWELL, A.; EWBANK, R.; GODFREY, C.; HOLGATE, B.; INGLIS, I.; JAMES, R.; PAGE, C.; SHARMAN, I.; VERSCHOYLE, R.; WESTALL, L.; WILSON, B. Refining procedures for the administration of substances. Lab. Anim., v.35, p.1-41, 2001.

SASHIDHARA, K.V.; KUMAR, A.; CHATTERJEE, M.; RAO, K.; SINGH, S.; VERMA, A.; PALIT, G. Discovery and synthesis of novel 3-phenylcoumarin derivatives as antidepressant agents. Bioorg. Med. Chem. Lett., v.21, n.7, p.1937-1941, 2011.
SONG, M.; LEE, D.; KIM, S.; BAE, J.; LEE, J.; GONG, Y.; LEE, T.; LEE, S. Identification of metabolites of N-(5-Benzoyl-2-(4-(2-Methoxyphenyl)piperazin-1-yl) thiazol-4-yl)pivalamide including CYP3A4-Mediated $\mathrm{C}$-Demethylation in human liver microsomes with highresolution/high-accuracy tandem mass. Drug Metab. Dispos., v.42, n.8, p.1252-1260, 2014.

TURNER, P.V.; BRABB, T.; PEKOW, C.; VASBINDER, M. Administration of substances to laboratory animals: routes of administration and factors to consider. J. Am. Assoc. Lab. Anim. Sci., v.50, n.5, p.600-613, 2011.

WEI, L.; WANG, X.; ZHANG, P.; SUN, Y.; JIA, L.; ZHAO, J.; DONG, S.; SUN, L. An UPLC-MS/MS method for simultaneous quantitation of two coumarins and two flavonoids in rat plasma and its application to a pharmacokinetic study of Wikstroemia indica extract. $J$. Chromatogr. B: Analyt. Technol. Biomed. Life Sci., v.1008, n.1, p.139-145, 2016.

WEI-QIN, T. Molecular and physicochemical propierties impacting oral absortion of drugs. In: KRISHNA, R.; YU, L. (Eds.). Biopharmaceutics applications in drug development. New York: Springer, 2008. p.36.

YUAN, Z.; XU, H.; WANG, K.; ZHAO, Z.; HU, M. Determination of osthol and its metabolites in a phase I reaction system and the Caco- 2 cell model by HPLCUV and LC-MS/MS. J. Pharm. Biomed. Anal., v.49, n.5, p.1226-1232, 2009.

ZHANG, W.; DI, L.; LI, J.; SHAN, J.; KANG, A.; QIAN, S.; CHEN, L. The effects of Glycyrrhizae uralenis and its major bioactive components on pharmacokinetics of daphnetin in Cortex daphnes in rats. J. Ethnopharmacol., v.154, n.3, p.584-592, 2014.

Received for publication on $04^{\text {nd }}$ May 2016 Accepted for publication on $14^{\text {th }}$ October 2016 